\title{
Statistical analysis of annual maximum daily rainfall for Nelspruit and its environs
}

\begin{tabular}{|c|c|}
\hline \multicolumn{2}{|c|}{$\begin{array}{l}\text { Authors: } \\
\text { Eric M. Masereka }^{1} \\
\text { George M. Ochieng } \\
\text { Jacques Snyman }^{1}\end{array}$} \\
\hline \multicolumn{2}{|c|}{$\begin{array}{l}\text { Affiliations: } \\
{ }^{1} \text { Department of Civil } \\
\text { Engineering, Tshwane } \\
\text { University of Technology, } \\
\text { South Africa }\end{array}$} \\
\hline \multicolumn{2}{|c|}{$\begin{array}{l}{ }^{2} \text { Department of Civil } \\
\text { Engineering, Vaal University } \\
\text { of Technology, South Africa }\end{array}$} \\
\hline \multicolumn{2}{|c|}{$\begin{array}{l}\text { Corresponding author: } \\
\text { Eric Masereka, } \\
\text { maserekamaate@gmail.com }\end{array}$} \\
\hline \multicolumn{2}{|c|}{$\begin{array}{l}\text { Dates: } \\
\text { Received: } 28 \text { May } 2017 \\
\text { Accepted: } 01 \text { Aug. } 2017 \\
\text { Published: } 26 \text { Mar. } 2018\end{array}$} \\
\hline \multicolumn{2}{|c|}{$\begin{array}{l}\text { How to cite this article: } \\
\text { Masereka, E.M., Ochieng, } \\
\text { G.M. \& Snyman, J., 2018, } \\
\text { 'Statistical analysis of annual } \\
\text { maximum daily rainfall for } \\
\text { Nelspruit and its environs', } \\
\text { Jàmbá: Journal of Disaster } \\
\text { Risk Studies 10(1), a499. } \\
\text { https://doi.org/10.4102/ } \\
\text { jamba.v10i1.499 }\end{array}$} \\
\hline \multicolumn{2}{|c|}{$\begin{array}{l}\text { Copyright: } \\
\text { (C) 2018. The Authors. } \\
\text { Licensee: AOSIS. This work } \\
\text { is licensed under the } \\
\text { Creative Commons } \\
\text { Attribution License. }\end{array}$} \\
\hline \multicolumn{2}{|l|}{ Read online: } \\
\hline 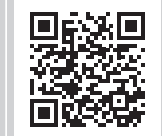 & $\begin{array}{l}\text { Scan this QR } \\
\text { code with your } \\
\text { smart phone or } \\
\text { mobile device } \\
\text { to read online. }\end{array}$ \\
\hline
\end{tabular}

Nelspruit and its environs frequently experience extreme high annual maximum daily rainfall (AMDR) events resulting in flood hazards. These flood hazards have caused flood disasters that have resulted in loss of property and lives. The main objective of this study was to carry out statistical analysis of extreme high AMDR events that have caused flood hazards, which in turn have caused flood disasters in Nelspruit and its environs. Empirical continuous probability distribution functions (ECPDF) and theoretical continuous probability distribution functions (TCPDF) were applied to carry out the statistical analysis of the extreme high AMDR events. Annual maximum daily rainfall event of magnitude $100 \mathrm{~mm}$ was identified as a threshold. Events $>100 \mathrm{~mm}$ were considered as extreme high events resulting in flood disasters. The results of empirical frequency analysis showed that the return period of flood disasters was 10 years. The occurrence probability of flood disaster event at least once in 1, 2, 3, 4 and 5 years was $0.10,0.19,0.27,0.34$ and 0.41 , respectively. Generalised logistic PDF was identified as the best-fit theoretical PDF for statistical analysis of the extreme high AMDR events in Nelspruit and its environs. The results of this study contributed to the understanding of frequency and magnitude of extreme high AMDR events that could lead to flood disasters. The results could be applied in developing flood disaster management strategies in Nelspruit and its environs.

\section{Introduction}

Extreme high annual maximum daily rainfall (AMDR) events are among environmental events that have caused the most disastrous consequences for human society (Kysely, Picek \& Huth 2006). Flood hazards caused by high extreme rainfall events have resulted in flood disasters that have accounted for $47 \%$ of all weather-related disasters affecting 2.3 billion people worldwide (Wahlstrom \& Guha-Sair 2015). Death tolls because of floods have also risen in many parts of the world. In 2007, floods killed 3300 people in India and Bangladesh alone; in 2010, floods killed 2100 people in Pakistan and 1900 people in China, whereas in 2013, 6500 people died because of floods in India (Wahlstrom \& Guha-Sair 2015). These flood events have been attributed to effects of human-induced climate change (Komi, Amisigo \& Diekkriiger 2016). In order to formulate and develop strategies to manage and reduce flood disaster risk, it is necessary to carry out statistical analysis of the AMDR events that cause these flood disasters.

Occurrences of floods in Nelspruit and its environs because of extreme high AMDR events have been documented. On 29 January 1974, heavy rains of $112.6 \mathrm{~mm}$ in $24 \mathrm{~h}$ caused floods that destroyed property in Nelspruit and its environs (SAWS 1994). On 29 January 1984, heavy rains of $110.5 \mathrm{~mm}$ in $24 \mathrm{~h}$ caused floods in which four lives were lost and several agricultural dams were destroyed (Kovacs et al 1984). On 08 February 1985, $126.0 \mathrm{~mm}$ of rain in $24 \mathrm{~h}$ caused damage to roads and bridges in Nelspruit and its environs (SAWS 1985). The heavy rains and storms of $106.2 \mathrm{~mm}$ on 06 February 2000 followed by $102.8 \mathrm{~mm}$ on 07 February 2000 caused a lot of damage. It was estimated that $1240 \mathrm{~km}$ of paved roads, $1306 \mathrm{~km}$ of gravel roads, $120 \mathrm{~km}$ of farm roads and 84 bridges were damaged. Also, these floods destroyed 16 large dams and 96 small farm dams (Smithers et al. 2000). On 18 January 2012, heavy rains of $109.0 \mathrm{~mm}$ caused floods and extensive damage in Nelspruit and its environs (News24 2012). On 11 March 2014, heavy rains of $107.3 \mathrm{~mm}$ in $24 \mathrm{~h}$ which was followed by $104.8 \mathrm{~mm}$ of rain of the previous $24 \mathrm{~h}$ caused the death of 11 people in Nelspruit and its environs (News24 2014).

The areas that have been affected by flood hazards are mainly in the river courses and more so in the flood zones. Bridges, water pumping stations, farm roads and irrigation systems are among the infrastructures that are frequently affected by flood hazards.

Despite the frequent extreme high AMDR events that have been causing floods resulting in loss of human lives and property, limited research has been carried out on the frequency and magnitude 
of extreme high AMDR events in Nelspruit and its environs (SAWS 2014).

Approaches to reduce flood disaster risk caused by extreme high AMDR include flood disaster mitigation, early warning systems, disaster preparedness, recovery and support livelihood (Komi et al. 2016). Of these approaches, flood mitigation plays a pivotal role. Mitigation of flood disaster can be carried out in two methods, namely engineering method to control floods and regulatory method designed to decrease flood vulnerability (Komi et al. 2016). The engineering method includes construction of structures like channel modifications, retention walls, levees and dikes. The regulatory method includes flood plain zoning and building construction codes. Results of statistical analysis of high extreme AMDR events are necessary to develop and formulate methods and strategies for flood disaster reduction and mitigation.

The aim of this study was to carry out statistical analysis of extreme high AMDR events which cause flood hazards that result in flood disasters in Nelspruit and its environs. The other objective of the study was the identification of the theoretical probability distribution function(s) (PDF) that best describe these extreme high AMDR events which cause flood hazards that result in flood disasters in Nelspruit and its environs.

The initial studies of rainfall events that caused flood disasters in Nelspruit and environs were concentrated on atmospheric mechanisms that resulted in these heavy rainfall events. Simpson (1996) studied cumulus clouds and the associated larger mesoscale systems that produced heavy storms in and around Nelspruit Schulze (1972) from his studies concluded that there was a high incidence of hail and thunder in North Eastern region of South Africa. Kelbe (1984) studied cumulus cloud characteristics and observed that most of the severe storms occurred in the early summer months in the radius of $50 \mathrm{~km}$ around Nelspruit. Studies on variability and probability of rainfall in relation to coefficients of variation of monthly and annual rainfall series at Nelspruit have been carried out. Green (1969) came to a conclusion that the Type 111 model, which had two independent parameters $\mathrm{q}$ and $\mathrm{p}$, was widely applicable in describing probability of monthly rainfall series. Recently, Mackellar, New and Jack (2014) in the study of observed and modelled trends in rainfall and temperature for South Africa for the period of 1960-2010 reported that a cluster of rainfall stations in the Lowveld in Mpumalanga showed increase in precipitation. None of the cited studies were focused on the frequency and magnitude analysis of extreme high AMDR events which caused flood hazards that resulted in flood disasters in Nelspruit and its environs. This study was therefore carried out to fill the gap of frequency and magnitude analysis of AMDR events which cause flood hazards that result in flood disasters in Nelspruit and its environs which was the focus of this study.

The steps of statistical analysis of hydrometeorological events involve selecting PDF to describe the phenomenon of interest, estimating parameters of that function and thus obtaining the risk estimates of satisfactory accuracy for the problem at hand (Stedinger, Vogel \& Batchelder 2001). Several PDFs have been selected and applied for frequency analysis of rainfall events. In United States of America (USA), Naghavi and Yu (1995) applied generalised extreme value (GEV) distribution function and found it suitable for frequency and magnitude analysis of AMDR events in Louisiana State. Daud et al. (2002) identified GEV as the best-fit PDF for frequency analysis of AMDR events in Malaysia. Park et al. (2010) also identified GEV as the bestfit PDF for frequency analysis of AMDR events in South Korea. However, other PDFs have also been identified as best-fit PDFs for frequency analysis of AMDR events. Olumide, Saidu and Oluwasesan (2013) in the study of frequency analysis of rainfall events at Tagwai Dam in Nigeria identified normal and Log-Gumbel PDFs as the best-fit PDFs for frequency analysis of the AMDR events. Goula Bi et al. (2010) identified and applied Gumbel and log normal PDFs for frequency analysis of AMDR events at 43 rainfall stations in Cot de Ivoire. Mason et al. (1999) identified Beta-K and Beta-P distributions as the best-fit PDFs for frequency analysis of AMDR events in South Africa. Du Plessis and Burger (2015) identified GEV as the best-fit distribution function to analyse the frequency of short-duration rainfall intensities in Western Cape Province in South Africa. In the study of cumulus cloud characteristics of the Eastern Transvaal Lowveld, rainfall events of $100 \mathrm{~mm}$ or more in $24 \mathrm{~h}$ were identified as the events that resulted in floods in Nelspruit and its environs (Kelbe 1984). In this study, AMDR event of magnitude of $100 \mathrm{~mm}$ was adopted as a threshold. AMDR events of greater than $100 \mathrm{~mm}$ were considered as events which cause flood hazards resulting in flood disasters. Also in this study, a method based on ranking of statistics of chi-squared (CS), KolmogorovSmirnov (KS) and Anderson-Darling $\left(A^{2}\right)$ goodness-of-fit tests developed by Masereka et al. (2015) were applied to selected candidate and best-fit PDF for the analysis of magnitude and frequency of the AMDR events in Nelspruit and its environs.

\section{Materials and methods Location and climate}

Nelspruit is located $330 \mathrm{~km}$ east of Pretoria in Crocodile River catchment (Figure 1). Crocodile River catchment is part of Incomati catchment (Figure 2). Its geographical coordinates are $25^{\circ} 27^{\prime} \mathrm{S}$ and $30^{\circ} 58^{\prime} \mathrm{E}$. Its altitude is $667 \mathrm{~m}$ a.s.l. Nelspruit normally receives about $667 \mathrm{~mm}$ of rain per year with most rainfall occurring in months of December, January, February and March. On average, it receives the lowest rainfall $(2 \mathrm{~mm})$ in June and the highest rainfall $(119 \mathrm{~mm})$ in December. The monthly distribution of average daily maximum temperatures shows that the average midday temperatures for Nelspruit range from $21.4{ }^{\circ} \mathrm{C}$ in June to $27.9^{\circ} \mathrm{C}$ in January. The region is the coldest during July when the temperature drops to $6.2^{\circ} \mathrm{C}$ on average during the night. Maps of Crocodile River catchment and Incomati catchment are shown in Figures 1 and 2. 


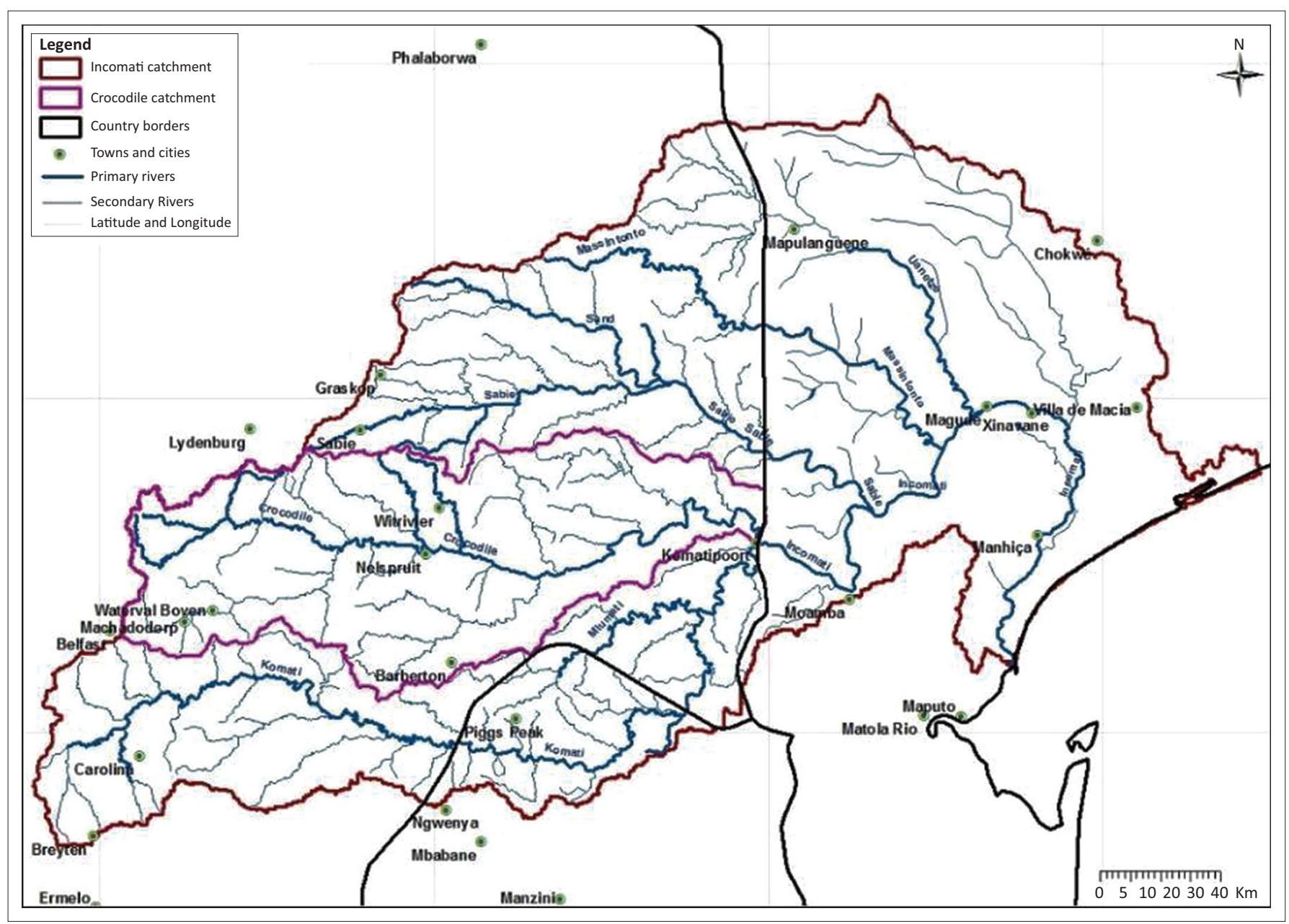

Source: DWS Nelspruit Office, 2017, The Inkomati catchment management strategy, viewed 12 February 2017, from http://www.dwaf.gov.za/IO/CMA/Inkomati/InkomaticMASQReportMar08full.pdf FIGURE 1: Drainage system of Incomati catchment showing the position of Nelspruit and its environs.

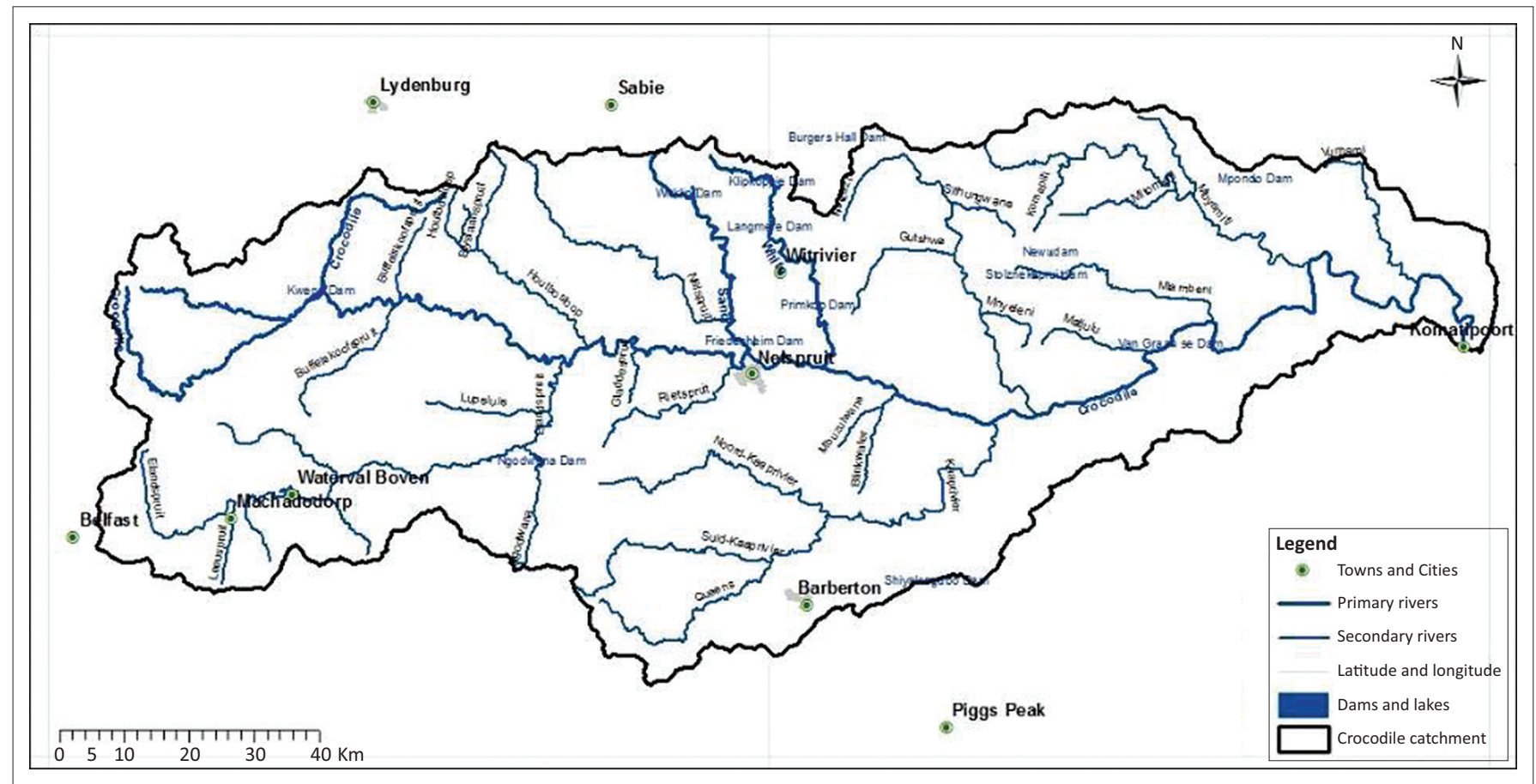

Source: DWS Nelspruit Office, 2017, The Inkomati catchment management strategy, viewed 12 February 2017, from http://www.dwaf.gov.za/IO/CMA/Inkomati/InkomaticMASQReportMar08full.pdf FIGURE 2: The Crocodile River catchment showing Nelspruit and its environs. 


\section{Data}

The daily rainfall (mm) data for the years 1961-2015 for Nelspruit were obtained from WR 90 and WR 2005 studies, which were carried out by Water Research Council (WRC) (Middleton \& Bailey 2005). In these studies, the methods of ensuring and improving quality of daily rainfall data including data used in this study were outlined (Middleton \& Bailey 2005). From the daily rainfall data of each year, the largest annual daily rainfall event was extracted. The extracted largest annual daily rainfall events for the years 1961-2015 formed the AMDR events. The AMDR events for the period 1961-2015 are presented in Table 1.

\section{Methodology Empirical frequency analysis}

Empirical continuous probability distribution function (ECPDF) was applied to determine the return periods of the AMDR events for Nelspruit and its environs for the period 1961-2015. The probability of exceedances $(p)$ of the AMDR events was determined by the rank-order method. This method involved ordering the events from the largest event to the smallest event. Rank 1 was assigned to the largest event and rank 55 to the smallest event. The data sample size was 55 events.

To obtain $p$ of each event, Weibull formula (Weibull 1939) was applied:

$p=\mathrm{i} / \mathrm{n}+1$

$p$ is the exceedance probability for an event with rank $\mathrm{i}$, $\mathrm{i}$ is the rank of the event, $\mathrm{n}$ is the sample size that was equal to 55 in this case. The return period (T) of each event is defined as the inverse of its exceedance probability (Weibull 1939):

$$
T=1 / p
$$

[Eqn 2]

The empirical return period of each AMDR event was determined by applying equation 2 .

\section{Flood disaster risk analysis}

The AMDR events $\geq 100 \mathrm{~mm}$ were identified as the events that caused flood hazards resulting in flood disasters in Nelspruit and its environs (Kelbe 1984). AMDR event of magnitude $100 \mathrm{~mm}$ was adopted as threshold. AMDR events of magnitude $100 \mathrm{~mm}$ or $\geq 100 \mathrm{~mm}$ were taken as flood causing events, therefore flood disaster events. Based on this adoption, the model for flood disaster risk analysis (exceedance probability of event $X$ being equal to or greater than threshold $x_{T}$ at least once in $N$ years) was developed as demonstrated below.

Letting $x_{T}$ be the threshold of AMDR variable. The exceedance probability $(p)$ of $X$ being equal to or greater than $x_{T}$ at least once in $N$ years of record was formulated as:
TABLE 1: Annual maximum daily rainfall (mm) events for Nelspruit (1961-2015)

\begin{tabular}{|c|c|}
\hline Year & Rainfall (mm) \\
\hline 1961 & 88.40 \\
\hline 1962 & 36.80 \\
\hline 1963 & 0.00 \\
\hline 1964 & 56.50 \\
\hline 1965 & 56.20 \\
\hline 1966 & 65.10 \\
\hline 1967 & 72.20 \\
\hline 1968 & 57.60 \\
\hline 1969 & 57.00 \\
\hline 1970 & 37.70 \\
\hline 1971 & 67.20 \\
\hline 1972 & 75.60 \\
\hline 1973 & 0.00 \\
\hline 1974 & 112.60 \\
\hline 1975 & 58.00 \\
\hline 1976 & 72.40 \\
\hline 1977 & 40.60 \\
\hline 1978 & 60.50 \\
\hline 1979 & 57.00 \\
\hline 1980 & 77.00 \\
\hline 1981 & 59.40 \\
\hline 1982 & 55.30 \\
\hline 1983 & 78.00 \\
\hline 1984 & 110.50 \\
\hline 1985 & 126.00 \\
\hline 1986 & 49.50 \\
\hline 1987 & 64.70 \\
\hline 1988 & 73.20 \\
\hline 1989 & 43.50 \\
\hline 1990 & 57.70 \\
\hline 1991 & 83.50 \\
\hline 1992 & 48.00 \\
\hline 1993 & 24.50 \\
\hline 1994 & 46.80 \\
\hline 1995 & 47.40 \\
\hline 1996 & 81.40 \\
\hline 1997 & 46.00 \\
\hline 1998 & 56.00 \\
\hline 1999 & 74.80 \\
\hline 2000 & 106.20 \\
\hline 2001 & 34.60 \\
\hline 2002 & 52.20 \\
\hline 2003 & 37.10 \\
\hline 2004 & 44.20 \\
\hline 2005 & 67.00 \\
\hline 2006 & 89.20 \\
\hline 2007 & 64.50 \\
\hline 2008 & 55.60 \\
\hline 2009 & 100.30 \\
\hline 2010 & 57.90 \\
\hline 2011 & 68.80 \\
\hline 2012 & 102.40 \\
\hline 2013 & 79.00 \\
\hline 2014 & 97.30 \\
\hline 2015 & 37.80 \\
\hline
\end{tabular}

$p=P\left(X \geq x_{T}\right)$

[Eqn 3]

$P=p\left(X<x_{T}\right)=(1-p)$

[Eqn 4] 
$P\left(X \geq x_{T}\right.$ at least once in $N$ years $)=1-P\left(X<x_{T}\right.$ all $N$ years $)$

[Eqn 5]

$P\left(X \geq x_{T}\right.$ at least once in $N$ years $)=1-(1-p)^{N}=1-\left(1-\frac{1}{T}\right)^{N}$

[Eqn 6]

Equation 6 was applied to determine the occurrence probability of flood disaster risk associated with AMDR events of magnitude $\geq 100 \mathrm{~mm}$ at least once in 1, 2, 3, 4 and 5 years.

\section{Stochastic frequency analysis}

Theoretical continuous probability distribution functions (TCPDFs) were applied to estimate quantiles of AMDR events of return periods up to 50 years. The estimation of the quantiles was carried out by first identifying the TCPDFs which adequately fitted the AMDR events. Masereka et al. (2015) have developed a methodology to identify candidate and best-fit TCPDFs for frequency analysis of hydrometeorological events. This methodology was adopted to identify candidate and best-fit TCPDFs for frequency analysis of the AMDR events. The identified candidate TCPDFs were subjected to three goodness-of-fit tests, namely CS, Kolmogorov-Smirnov (KS) and Anderson-Darling (AD), to identify the best-fit TCPDF.

\section{Description of the goodness-of-fit tests}

Three goodness-of-fit tests which were applied to identify the best-fit TCPDF from the candidate TCPDFs are described below.

\section{Chi-square $\left(x^{2}\right)$ test}

Chi-square $\left(x^{2}\right)$ is a goodness-of-fit test that compares how well the TCPDF fits the ECPDF. The chi-square statistic is defined as (Olofintoye, Sule \& Salami 2009):

$x^{2}=\sum_{i=1}^{k} \frac{\left(O_{i}-E_{i}\right)^{2}}{E_{i}}$

where $x^{2}$ is the test statistic, $O_{1}$ is the observed frequency in each category and $E_{l}$ is the expected (theoretical) frequency in the corresponding category calculated by:

$$
E_{l}=F\left(x_{2}\right)-F\left(x_{1}\right)
$$

where $F$ is the cumulative distribution function (CDF) of TCPDF being tested, and $x_{1}$ and $x_{2}$ are the lower and upper limits of category $\mathrm{i}$, where $i$ runs from $1, \ldots \ldots \ldots k$ and $k$ is the number of cells.

\section{Kolmogorov-Smirnov test}

The Kolmogorov-Smirnov (KS) test is a non-parametric test applied to test whether the sample under consideration is from a reference or hypothesised distribution or to compare whether two samples come from identical distribution (Kottegoda \& Rosso 1998). The KS test statistics are calculated from the largest vertical difference in absolute value between the theoretical value and the empirical cumulative distribution functions.

By definition, if a random sample, $x_{1}, x_{2} \ldots \ldots \ldots x_{n^{\prime}}$ is from the same distribution with CDF $F\left(x_{1}\right)$, then KS test statistic $D=\max \left(D^{+}, D^{-}\right)$where:

$D^{+}=\max \left(\frac{i}{n}-F\left(x_{1}\right)\right)$ [Eqn 9]

and

$D^{-}=\max \left(F\left(x_{1}\right)-\frac{i-1}{n}\right)$

\section{Anderson-Darling test}

Anderson-Darling $\left(A^{2}\right)$ is a goodness-of-fit test in which the fitting of an observed continuous PDF (sample) to an expected continuous PDF (parent) is carried out.

The test statistic $A^{2}$ is defined as (Mzezewa, Misi \& Van Rensburg 2010):

$A^{2}=-n-\frac{i}{n} \sum_{i=1}^{n}(2 i-1)\left[\ln F\left(x_{1}\right)+\ln \left(1-F\left(x_{n-i+1}\right)\right)\right]$ [Eqn 11]

where $n$ is the number of events in the sample.

\section{Identification of candidate theoretical continuous probability distribution functions}

From the AMDR data, probability-probability(P-P) plots were constructed and applied to visually identify the candidate TCPDFs for analysis of magnitude and frequency of AMDR events. The application of P-P plots involved plotting ECPDF values against TCPDF values of 50 continuous and discrete PDFs supported by EasyFit software (Mathwave 2015). The three TCPDF curves closest to the diagonal of the plots were selected as the candidate TCPDFs (Mathwave 2015).

Quantile-quantile (Q-Q) plots were applied to confirm the identified candidate TCPDFs. The application of Q-Q plot involved plotting the AMDR data: $X_{i}(i=1 \ldots .55)$ against the $\mathrm{X}$-axis, and the corresponding values against the $\mathrm{Y}$ - axis: $F^{-1}\left(F_{n}\left(X_{\mathrm{i}}\right)-0.5 / \mathrm{n}\right)$, where $F^{-1}(X)$ is the inverse cumulative TCPDF and $F_{n}(X)$ is the ECPDF. The proximity of the TCPDF plots to the displayed diagonal in EasyFit graph indicated the confirmation of the candidate TCPDFs (Mathwave 2015).

\section{The best-fit theoretical continuous probability distribution function}

Based on the test statistics: $X^{2}, \mathrm{KS}$ and $A^{2}$ of each candidate TCPDF, the candidate TCPDFs were ranked. The candidate 
TCPDF with the lowest test statistic was ranked 1 and the candidate TCPDF with the largest test statistic was ranked 3. The total number of identified candidate TCPDF was 3 . The candidate TCPDF with the least sum of ranks from the three goodness-of-fit was considered to be the best-fit TCPDF for the analysis of magnitude and frequency of the AMDR events.

\section{Quantile function}

The parameters of the identified best-fit TCPDF were estimated using maximum likelihood method using EasyFit 5.5 software (Mathwave 2015:7). Based on the PDF of the identified best-fit TCPDF, the estimated parameters were applied to develop quantile function (QF) (Mathwave 2015). The developed QF was applied to estimate quantiles of AMDR of return periods of $2,3,4,5,10,15,20,25$ and 50 years.

To determine how well the developed QF fitted the AMDR events, a probability difference (P-D) plot was constructed. $\mathrm{P}-\mathrm{D}$ plot is a plot of the difference between the ECPDF and the TCPDF (Mathwave 2015):

$$
\operatorname{Diff}(\mathrm{x})=F_{n}(X)-F(X)
$$

where $F_{n}(X)$ was the ECPDF and $F(X)$ was the identified best-fit TCPDF which was generalised logistic (GL).

\section{Confidence intervals of estimated quantiles}

The model (equation 13) proposed by Stedinger, Vogel and Foufoula-Georgiou (1993) to estimate 95\% confidence intervals of quantiles estimated by the application of GL distribution function was applied to determine the confidence intervals of estimated quantiles of return periods of $2,3,4,10$, 15, 20, 25 and 50 years:

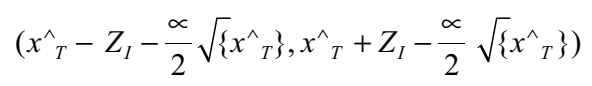

[Eqn 13]

where $Z_{I}-\frac{\propto}{2}$ is the upper $100(\propto / 2) \%$ percentile of the normal distribution. $x_{T}^{\wedge}$ is the estimated quantile of return period $(\mathrm{T})$.

\section{Results and discussions \\ Descriptive statistics of annual maximum daily rainfall events}

The descriptive statistics of AMDR events of Nelspruit for the period 1961-2015 are presented in Table 2.

The mean of AMDR events was $62.74 \mathrm{~mm}$. The median was $58.00 \mathrm{~mm}$. The Skewness of the AMDR events was positive
(0.09), indicating that the TCPDF of AMDR events had the tail that was on the right. This tail was longer or taller than on the left. These figures indicated that the AMDR events were not normally distributed.

\section{The plotting positions and return periods}

Equation 2 expresses the relationship between plotting positions of AMDR events and the corresponding empirical return periods that are presented in Table 2. The empirical return period of $100 \mathrm{~mm}$ AMDR event that has been adopted in this study as a threshold is 9.17 years (Table 3). Results of several studies have also shown that the return period of flood hazards that result in flood disasters in Nelspruit and its environs is 10 years (Kelbe 1984).

\section{Flood disaster risk analysis results}

In this study, the AMDR event of magnitude $100 \mathrm{~mm}$ was taken as threshold $\left(x_{T}\right)$ as indicated in sections above. AMDR events equal to or greater than $x_{T}$ were considered as flood disaster events. Taking $x_{T}=100 \mathrm{~mm}$, from the sample data in this study (Table 3), the number of occurrence of events $x_{T} \geq 100 \mathrm{~mm}$ was 6 , and the number of intervals was 5 . Therefore, the empirical return period of event $X_{T}$ was 10 years $(55 / 5=10$ years $)$.

The exceedance probability of flood disaster event (AMDR event: $X \geq 100 \mathrm{~mm}$ ) at least once in 1, 2, 3, 4 and 5 years calculated by applying equation 6 is presented in Table 4 .

The exceedance probability of flood disaster event $(\geq 100 \mathrm{~mm}$ ) occurring at least once in 5 years is 0.41 . The results are important for decision-making on the acceptable level of risk because of flooding that should be associated with designing specific to infrastructure for the reduction of the risk of flood in Nelspruit and environs.

\section{Candidate theoretical continuous probability distribution functions}

Applying P-P and Q-Q plots, GL, GEV and Gumbel maximum (GM) were identified as the candidate TCPDFs for frequency analysis of the AMDR events by visual identification method. The developed plots are presented in Figures 3 and 4 .

The P-P plot (Figure 3) showed that GL, GEV and GM distribution functions were closest to the plot diagonal. This indicated that the GL, GEV and GM were the candidate functions for frequency analysis of the AMDR events (Mathwave 2015). However, it was not possible to identify the best-fit TCPDF for describing the AMDR events. The Q-Q plot (Figure 4) showed that GL, GEV and GM distribution functions

TABLE 2: Descriptive statistics of maximum annual daily rainfall (1961-2015).

\begin{tabular}{lcccccccccc}
\hline Statistic value & Sample & Range & Mean & Variance & Standard deviation & Coefficient of variation & Standard error & Skewness & Excess kurtosis \\
\hline $\mathrm{V}$ & 55 & 126 & 62.74 & 611.87 & 24.74 & 0.39 & 3.33 & 0.09 & 0.87 & \\
\hline
\end{tabular}


TABLE 3: Plotting positions and return periods.

\begin{tabular}{|c|c|c|c|}
\hline$\underline{\mathbf{R}}$ & $X(\mathrm{~mm})$ & $\mathrm{Pi}$ & $\mathrm{T}$ (years) \\
\hline 1 & 126.00 & 0.02 & 55.00 \\
\hline 2 & 112.60 & 0.04 & 27.50 \\
\hline 3 & 110.50 & 0.05 & 18.33 \\
\hline 4 & 106.20 & 0.07 & 13.75 \\
\hline 5 & 102.40 & 0.90 & 11.00 \\
\hline 6 & 100.30 & 0.11 & 9.17 \\
\hline 7 & 89.20 & 0.13 & 7.86 \\
\hline 8 & 88.40 & 0.15 & 6.88 \\
\hline 9 & 83.50 & 0.16 & 6.11 \\
\hline 10 & 81.40 & 0.18 & 5.50 \\
\hline 11 & 79.30 & 0.20 & 5.00 \\
\hline 12 & 79.00 & 0.22 & 4.58 \\
\hline 13 & 78.00 & 0.24 & 4.23 \\
\hline 14 & 77.00 & 0.25 & 3.93 \\
\hline 15 & 75.60 & 0.27 & 3.67 \\
\hline 16 & 74.80 & 0.29 & 3.44 \\
\hline 17 & 73.20 & 0.31 & 3.24 \\
\hline 18 & 72.40 & 0.33 & 3.06 \\
\hline 19 & 72.20 & 0.35 & 2.89 \\
\hline 20 & 68.80 & 0.36 & 2.75 \\
\hline 21 & 67.20 & 0.38 & 2.62 \\
\hline 22 & 67.00 & 0.40 & 2.50 \\
\hline 23 & 65.10 & 0.42 & 2.39 \\
\hline 24 & 64.70 & 0.44 & 2.29 \\
\hline 25 & 64.50 & 0.45 & 2.20 \\
\hline 26 & 60.50 & 0.47 & 2.12 \\
\hline 27 & 59.40 & 0.49 & 2.04 \\
\hline 28 & 58.00 & 0.51 & 1.96 \\
\hline 29 & 57.90 & 0.53 & 1.90 \\
\hline 30 & 57.70 & 0.55 & 1.83 \\
\hline 31 & 57.60 & 0.56 & 1.77 \\
\hline 32 & 57.06 & 0.58 & 1.72 \\
\hline 33 & 57.00 & 0.60 & 1.67 \\
\hline 34 & 56.50 & 0.62 & 1.62 \\
\hline 35 & 56.20 & 0.64 & 1.57 \\
\hline 36 & 56.00 & 0.65 & 1.53 \\
\hline 37 & 55.60 & 0.67 & 1.49 \\
\hline 38 & 55.30 & 0.69 & 1.45 \\
\hline 39 & 52.20 & 0.71 & 1.41 \\
\hline 40 & 49.50 & 0.73 & 1.38 \\
\hline 41 & 48.00 & 0.75 & 1.34 \\
\hline 42 & 47.40 & 0.76 & 1.31 \\
\hline 43 & 46.80 & 0.78 & 1.28 \\
\hline 44 & 46.00 & 0.80 & 1.25 \\
\hline 45 & 44.20 & 0.82 & 1.22 \\
\hline 46 & 43.50 & 0.84 & 1.20 \\
\hline 47 & 40.60 & 0.85 & 1.17 \\
\hline 48 & 37.80 & 0.87 & 1.15 \\
\hline 49 & 37.70 & 0.89 & 1.12 \\
\hline 50 & 37.10 & 0.91 & 1.10 \\
\hline 51 & 36.80 & 0.93 & 1.08 \\
\hline 52 & 34.60 & 0.95 & 1.06 \\
\hline 53 & 24.50 & 0.96 & 1.04 \\
\hline 54 & 0.00 & 0.98 & 1.02 \\
\hline 54 & 0.00 & 0.98 & 1.02 \\
\hline
\end{tabular}

underestimated AMDR quantiles of magnitudes $<40 \mathrm{~mm}$. The three functions accurately estimated AMDR quantiles of magnitudes of the range $40 \mathrm{~mm}-95 \mathrm{~mm}$. Between $95 \mathrm{~mm}$ and $110 \mathrm{~mm}$, all the three models overestimated the quantiles. Quantiles > $110 \mathrm{~mm}$ were underestimated by GL and GEV
TABLE 4: Exceedance probability of flood disaster event ( $X \geq 100 \mathrm{~mm})$.

\begin{tabular}{lccccc}
\hline Year & $\mathbf{1}$ & $\mathbf{2}$ & $\mathbf{3}$ & $\mathbf{4}$ & $\mathbf{5}$ \\
\hline $\mathrm{P}(>100)$ & 0.10 & 0.19 & 0.27 & 0.34 & 0.41 \\
\hline
\end{tabular}

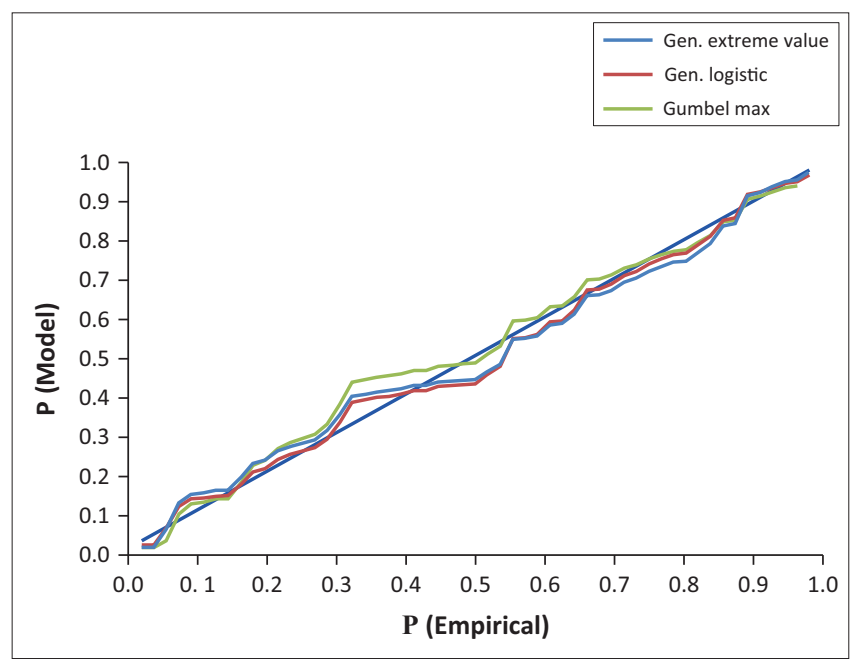

FIGURE 3: Probability-probability plot of annual maximum daily rainfall events for Nelspruit (1961-2015).

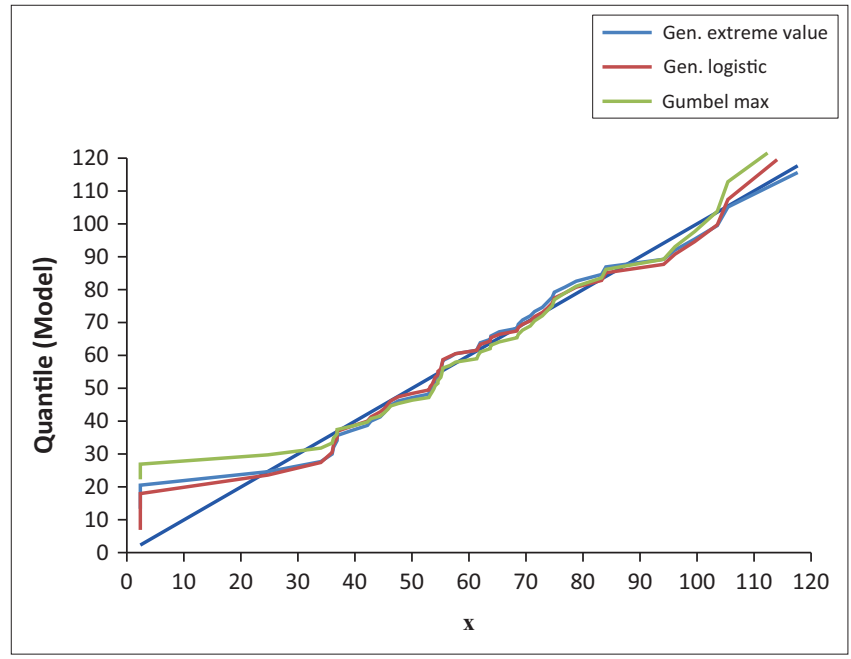

FIGURE 4: Quantile-quantile plot of annual maximum daily rainfall events for Nelspruit (1961-2015).

but overestimated by GM. The diagonal line of the Q-Q plot was the reference. If a distribution function curve lays on the diagonal, this indicates that the function accurately estimates the quantiles (Mathwave 2015).

\section{Best-fit theoretical continuous probability distribution function}

The results of identifying the best-fit PDF for frequency analysis of the AMDR events for Nelspruit and environs are presented in Table 5.

The rankings of the candidate TCPDFs as the best-fit TCPDFs for the frequency analysis of AMDR events based on statistics of the three goodness-of-fit tests are presented in Table 5. The candidate TCPDF with the least sum of the rankings was GL distribution. GL distribution was therefore identified as the best-fit TCPDF because it had the lowest sum of rankings. 
TABLE 5: Best-fit distribution.

\begin{tabular}{|c|c|c|c|c|c|c|c|}
\hline \multirow[t]{2}{*}{ TCPDF } & \multicolumn{2}{|c|}{ Kolmogorov-Smirnov } & \multicolumn{2}{|c|}{ Anderson-Darling } & \multicolumn{2}{|c|}{ Chi-squared } & \multirow[t]{2}{*}{ Rank sum } \\
\hline & Statistic & Rank & Statistic & Rank & Statistic & Rank & \\
\hline Generalised extreme value (GEV) & 0.09125 & 2 & 0.56426 & 2 & 4.6075 & 3 & 7 \\
\hline Generalised logistic (GL) & 0.07556 & 1 & 0.31126 & 1 & 3.0771 & 1 & 3 \\
\hline Gumbel max (GM) & 0.12881 & 3 & 1.18240 & 3 & 3.3621 & 2 & 8 \\
\hline
\end{tabular}

TCPDF, Theoretical continuous probability distribution functions.

\section{Generalised logistic probability distribution function}

Generalised logistic PDF is defined by the QF as (Shin et al. 2011):

$$
X_{T}=\sum+\frac{\alpha}{\beta}\left[1-(T-1)^{-\beta}\right]
$$

$\alpha$ is the scale parameter, $\beta$ is the shape parameter, $\Sigma$ is the location parameter.

The parameters, $\Sigma, \alpha$ and $\beta$, were estimated by applying the method of maximum likelihood (ML) in Mathwave software (Mathwave 2015). These parameters are shown in Table 6.

The specific QF of GL probability function for estimating AMDR events for Nelspruit and environs was developed based on the parameters in Table 6 as indicated in Equation 15:

$$
X_{T}=61.61+271.60\left[1-(T-1)^{-0.05}\right]
$$

Equation 15 was applied to estimate quantiles of return periods $2,3,4,5,10,15,20,25$ and 50 years. The estimated quantiles are presented in Table 7.

The estimated quantiles of the AMDR events of return periods between 2 and 50 years which were obtained by applying equation 15 are presented in Table 7 . The comparison of results of magnitude analysis of the AMDR events based on ECPDFs and TCPDFs (Table 7) shows that GL PDF fairly accurately estimates the AMDR events of magnitudes $61.61 \mathrm{~mm}-101.51 \mathrm{~mm}$. The performance of GL PDF in estimating magnitudes of AMDR events is further demonstrated by the Q-Q plot results. The Q-Q plot based on GL PDF is presented in Figure 5.

The GL PDF was identified as the best-fit TCPDF in this study (Table 5). It should be noted that GL PDF accurately estimated the annual maximum daily rainfall events of range $40 \mathrm{~mm}-$ $90 \mathrm{~mm}$ (Figure 5). This range corresponds to quantiles of return period range 1.38-7.86 years (Table 1, Figure 5). GL PDF overestimated AMDR events of range $90 \mathrm{~mm}-112 \mathrm{~mm}$ (Figure 5). This range corresponds to quantiles of return period range 9.17-27.50 years (Table 1, Figure 5). GL PDF under estimated the annual maximum daily rainfall events which were $>112 \mathrm{~mm}$ (Figure 5). These results demonstrate the fact that even the magnitude estimates obtained from the identified best-fit TCPDF should be used in infrastructure design with caution.
TABLE 6: Estimated parameters.

\begin{tabular}{lc}
\hline Distribution & Parameters \\
\hline Generalised logistic & $\beta=0.05, \alpha=13.58, \sum=61.61$ \\
\hline
\end{tabular}

TABLE 7: Quantile-return period.

\begin{tabular}{cccccccccc}
\hline $\mathbf{R T}$ (YRS) & $\mathbf{2}$ & $\mathbf{3}$ & $\mathbf{4}$ & $\mathbf{5}$ & $\mathbf{1 0}$ & $\mathbf{1 5}$ & $\mathbf{2 0}$ & $\mathbf{2 5}$ & $\mathbf{5 0}$ \\
\hline $\mathrm{X}_{T}(\mathrm{~mm})$ & 61.61 & 70.86 & 76.13 & 79.80 & 89.87 & 95.19 & 98.79 & 101.51 & 109.64 \\
\hline
\end{tabular}

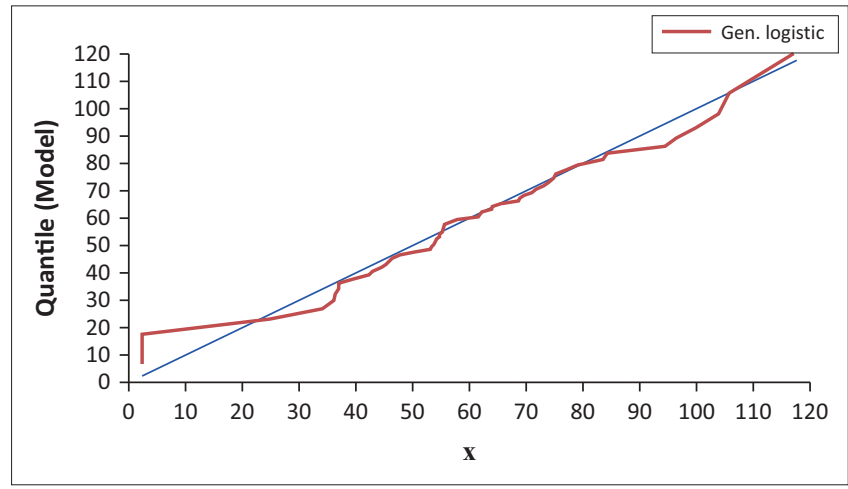

FIGURE 5: Quantile-quantile plot of the annual maximum daily rainfall events for Nelspruit (1961-2015).

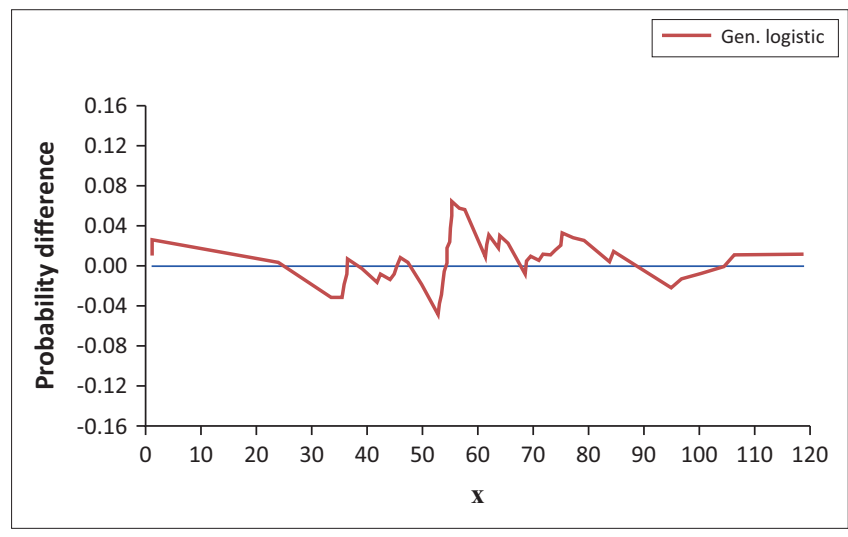

FIGURE 6: Probability-difference plot between empirical continuous probability distribution function and generalised logistic probability distribution function for annual maximum daily rainfall events for Nelspruit (1961-2015).

\section{P-D plot results}

The results of probability difference (P-D) plot between ECPDF (based on the sample) and GL PDF are presented in Figure 6.

The P-D plot (Figure 6) showed that the probability difference between the AMDR events (the sample) and the quantiles estimated by GL $>100 \mathrm{~mm}$ is $<0.03(3 \%)$. This showed that GL estimated the quantiles $>100 \mathrm{~mm}$ fairly accurately.

\section{Confidence intervals}

The $95 \%$ confidence interval of the estimated quantiles is presented in Table 8. 
TABLE 8: Confidence intervals of estimated quantiles.

\begin{tabular}{|c|c|c|c|c|c|c|c|c|c|}
\hline Return period T (years) & 2 & 3 & 4 & 5 & 10 & 15 & 20 & 25 & 50 \\
\hline$x_{T}^{\wedge}$ Upper limit & 67.92 & 82.14 & 93.22 & 96.89 & 122.00 & 135.89 & 138.37 & 143.53 & 154.17 \\
\hline${ }^{\wedge}{ }_{T}$ & 61.61 & 70.86 & 76.86 & 79.80 & 89.87 & 95.19 & 98.79 & 101.51 & 109.64 \\
\hline$x_{T}^{\wedge}$ Lower limit & 55.30 & 56.02 & 57.91 & 58.01 & 63.91 & 64.51 & 65.23 & 66.41 & 67.32 \\
\hline
\end{tabular}

From the confidence intervals, the relative size of uncertainty at different return periods and the importance of different sources of uncertainty could be determined (Kjeldsen \& Jones 2004). However, this was not part of this study.

\section{Discussions of the results}

\section{Identification of the threshold}

From the literature, AMDR events of magnitude $100 \mathrm{~mm}$ or greater led to flood hazards which resulted in flood disasters in Nelspruit and its environs. Records of flood disasters from 1974 to 2014 cited in this article indicated that flood hazards which resulted in flood disasters in that period were caused by AMDR events of magnitudes $\geq 100 \mathrm{~mm}$. The AMDR event of magnitude $100 \mathrm{~mm}$ was adopted as a threshold. The AMDR events of magnitude $\geq 100 \mathrm{~mm}$ were assumed to be flood disaster events.

\section{Return period based on empirical distribution function and plotting point method}

From the empirical distribution function frequency analysis, the return period of $100 \mathrm{~mm}$ AMDR event was 10 years. The return period of $100 \mathrm{~mm}$ AMDR event was 9.17 years according to plotting point applying Weibull (1939) method (Table 3). The estimate of the return periods from the two methods was in agreement. The results indicated that if the design return period of a hydraulic infrastructure being designed is less or equal to data record period, estimation of quantiles by empirical distribution function or plotting point methods is recommendable.

\section{Best-fit theoretical continuous probability distribution function}

Generalised logistic probability distribution function was identified as the best-fit function for frequency analysis of AMDR events in Nelspruit and environs. In other studies elsewhere, different TCPDFs have been identified as the bestfit TCPDFs for frequency analysis of AMDR events. In USA, GEV was identified as the best-fit PDF for frequency analysis of AMDR events (Bonnin et al. 2006; Naghavi \& Yu 1995). In Malaysia, Daud et al. (2002) identified Log-Gumbel as the best-fit function for frequency analysis of AMDR events. In Cote de Ivoire, Goula Bi et al. (2010) identified Gumbel and Lognormal functions as the best-fit TCPDFs for frequency analysis of AMDR events in Cote de Ivoire, and Smithers and Schulze (2001) proposed Log Pearson 3 function as the bestfit PDF for AMDR events in South Africa.

The performance of GL TCPDF was assessed by applying Q-Q and P-D plots (Figures 4 and 5). Both plots affirmed that the performance of GL was satisfactory. However, there seem to be no universally accepted TCPDF for frequency analysis of AMDR events. Therefore, it is advisable to carry out bestfit TCPDF identification study first for designing any hydro meteorological infrastructure projects in specific regions or sites rather than just adopting any TCPDF.

\section{Practical implication}

The results of the study are applicable in flood hazard mapping. The results can also be applied in formulating mitigation of flood hazard in two ways. An engineering approach in designing flood control structures, for example designing and planning storm water and flood management and control infrastructure like urban drainage systems, culverts and bridges. Regulatory approach designed to reduce vulnerability, for example flood plain zoning. The results of the study can also be applied in formulating methods of flood disaster risk reduction which include, among others, among others disaster preparedness.

\section{Limitations}

The main limitation of the study was the short period of record of daily rainfall events data from which the AMDR events were extracted. The record was only 55 years. Length of record data affects the performance of empirical distribution function to estimate return period of magnitudes and therefore the associated risks. The performance is poor with short records. Deciding on the magnitude of AMDR events as a threshold for frequency analysis was another limitation.

\section{Recommendations}

Further studies on the topics below are recommended:

- Hydrological deterministic studies should be carried out to determine the critical magnitude of AMDR events which result in flood disaster. The magnitude of $100 \mathrm{~mm}$ applied in this study was adopted from literature.

- Further studies are recommended for determining the best-fit PDF for analysis of frequency and magnitude of AMDR events. The goodness-of-fit method applied in this study should be tested with data from other catchments.

- A study on the effect of climate change on magnitude and frequency of AMDR events should be carried out.

\section{Conclusion}

The main objective of this study was to carry out statistical analysis of AMDR events for Nelspruit and its environs. 
From literature, AMDR events of magnitude $100 \mathrm{~mm}$ or more were identified as events that cause flood hazards resulting in flood disasters in Nelspruit and its environs. From the study, the return period of AMDR event of magnitude $100 \mathrm{~mm}$ in Nelspruit and its environs was 10 years. The occurrence probability of AMDR events of magnitude $100 \mathrm{~mm}$ or more at least once was $0.01,0.19,0.27,0.34$ and 0.41 in 1,2 , 3,4 and 5 years, respectively. These results can be applied in developing systems that can be applied in disaster risk reduction in Nelspruit and its environs.

From the study, GL, GEV and GM theoretical PDFs were identified as the suitable candidate TCPDFs for frequency analysis of maximum annual daily rainfall events of Nelspruit and its environs. From the three candidate TCPDFs, GL was identified as the best-fit TCPDF for frequency and magnitude analysis of AMDR events in Nelspruit and environs. The performance of GL as the best-fit PDF for frequency analysis of AMDR events was evaluated by the use of Q-Q and D-P plots. The performance was found to be satisfactory. It was therefore concluded that GL PDF is suitable for frequency analysis of AMDR events for Nelspruit and its environs.

\section{Acknowledgements}

The study was funded by the Department of Agriculture Mpumalanga Province. The data were accessed from the work performed for WRC. Supervision of the study was performed by Prof. G.M. Ochieng of Vaal University of Technology and Prof. J. Synman of Tshwane University of Technology.

\section{Competing interests}

The authors declare that they have no financial or personal relationships that may have inappropriately influenced them in writing this article.

\section{Authors' contributions}

E.M.M. carried out the research. G.M.O. and J.S. supervised the research.

\section{References}

Bonnin, G.M., Martin, D., Lin, B., Parzybok, T., Yekta, M. \& Riley, D., 2006, Precipitation frequency Atlas of the United States. NOAA Atlas 14, vol. 3, version 4.0: Puerto Rico and the U.S. Virgin Islands, viewed 06 May 2017, from http://www.nws.noaa.gov

Daud, Z.M., Kassim, A.H.M., Desa, M.N.M. \& Nguyen, V.T.V., 2002, 'Statistical analysis of at-site extreme rainfall processes in peninsular Malaysia', International of at-site extreme rainfall processes in peninsular Malaysia', International
Association of Hydrological Sciences, Publication 274, 61-68. https://doi. Association of Hydrological
org/10.5923.c.jce.201402.38

Du Plessis, J.A. \& Burger, G.J., 2015, Investigation into increasing short-duration rainfall intensities in South Africa, viewed 15 May 2017, from http://www.wrc.org. za/pages/default.aspx

DWS Nelspruit Office, 2017, The Inkomati catchment management strategy, viewed 12 February 2017, from www.dwa.gov.za/01/InkomatiCMASQReport Mar08full.pdf

Goula Bi, T.A., Soro, G.E., Dao, A., Kouassi, F.W. \& Srohourou, B., 2010, 'Frequency analysis and new cartography of extremes daily rainfall events in Côte d'Ivoire, Journal of Applied Sciences 10, 1684-1694. https://doi.org/10.3923/jas.2010. 1684.1694

Green, G.C., 1969, 'Variability and probability of rainfall in relation to coefficients of variation of rainfall series', Agrochemophysica 1, 1-8.

Kelbe, B., 1984, 'Cumulus clouds characteristics of Eastern Transvaal Lowveld', Water SA 10(2), 81-93, viewed 20 February 2017, from http://www.acadamia. edu/1801540
Kjeldsen, T.R. \& Jones, D.A., 2004, 'Sampling variance of flood quantiles from the generalized logistic distribution using the method of L-moments', Hydrology and Earth System Sciences 8(2), 183-190, viewed 16 May 2017, from http://www. Earth System Sciences $8(2), 183-190, v$
hydrol-earth-syst-sci.net/8/183/2004

Komi, K., Amisigo, B.A. \& Diekkriiger, B., 2012, 'Integrated flood risk assessment of rural communities in the Oti River Basin, West Africa', Hydrology 3(4), viewed 15 April 2017, from http://www.mdpi.com/about/openaccess

Kottegoda, N.T. \& Rosso, R., 1998, Statistics probability and reliability for civil and environmental engineers, McGraw-Hill, New York, viewed 18 April 2017, from http://www.pwut.ac.ir/FA/Staff/S_Mousavi/.../Kottegoda.pdf

Kovacs, Z.P., Du Plessis, D.B., Bracher, P.R., Dunn, P. \& Mallory, G.C.L., 1984 Documentation of the 1984 Domoina Flood, viewed 17 May 2017, from http:// www.dwa.gov.za/iwgs/reports/tr_122_1984/domoina_floods.pdf

Kysely, J., Picek, J. \& Huth, R., 2006, 'Formation of homogenous regions for regional frequency analysis of extreme precipitation in the Czech Republic', Studia Geophysica et Geodaetica 51, 327-344.

Mackellar, N., New, M. \& Jack, C., 2014, 'Observed and modelled trends in rainfall and temperature for South Africa: 1960-2010', South African Journal of Science 1-13, viewed 13 May 2017, from http://www.sajs.co.z

Masereka, E.M., Otieno, F.A.O., Ochieng, G.M. \& Snyman, J., 2015, 'Best fit and selection of probability distribution models for frequency analysis of extreme mean annual rainfall events', International Journal of Engineering Research and Development 11(4), 34-53.

Mason, S.J., Waylen, P.R., Mimmack, G.M., Rajaratnam, B. \& Harrison, M.J., 1999 'Changes in extreme rainfall events in South Africa', Climatic Change 41, 249-257. https://doi.org/10.1023/A:1005450924499

Mathwave, 2015, Mathwave, viewed 20 May 2017, from http://www.mathwave. com./downloads.html

Middleton, B. \& Bailey, A.D., 2005, Water resources of South Africa. 2005 study (WR 2005) - 2011 update, viewed 21 May 2017, from http://www.wrc.org.za

Mzezewa, J., Misi, T. \& Van Rensburg, L.D., 2010, 'Characterisation of rainfall at a semiarid cotype in the Limpopo province (South Africa) and its implications for sustainable crop production', Water SA 36(1), 19-26, viewed 17 April 2017, from sustainable crop production', Water SA 36(1), 19-26, viewed 17 April 2017, fro
http://www.scielo.org.za/scielo.php\%3Fpid\%3DS1816-79502010000100003\%

Naghavi, B. \& Yu, F.X., 1995, 'Regional frequency analysis of extreme precipitation in Louisiana', Journal of Hydraulic Engineering 121(11), 819-827, viewed
12 May 2017, from http://www.serials.unibo.it/cgi-ser/start/it/spogli/df-s. tcl?prog_art $=3177745$

News24, 2012, Mpumalanga Floods, viewed 11 June 2017, from http://www.news24. com/SouthAfrica/Mpumalanga_Floods

News24, 2014, Mpumalanga Floods, viewed 11 June 2017, from http://www.news24. com/green/Mpumalanga_Floods

Olofintoye, O.O., Sule, B.F. \& Salami, A.W., 2009, 'Best-fit probability distribution model for peak daily rainfall of selected cities in Nigeria', New York Science Journa 2(3), viewed 30 May 2017, from http://www.sciencepub.net/NewYork

Olumide, B., Saidu, A.M. \& Oluwasesan, A., 2013, 'Evaluation of best fit probability distribution models for the prediction of rainfall and runoff volume (Case Study Tagwai Dam, Minna-Nigeria)', Engineering and Technology 3(2), 94-98, viewed 11 May 2017, from http://iet-journals.org/archive/2013/feb_vol_3_ no_2/635221356337.pdf

Park, J.S., Kang, H.S., Lee, Y.S. \& Kim, M.K., 2010, 'Changes in the extreme rainfall in South Korea', International Journal of Climatology 31, 2290-2299. https://doi. org/10.1002/joc.2236

SAWS, 1985, Flood reports, viewed 21 May 2017, from http://www.weathersa.co.za/ floods

SAWS, 1994, Flood reports, viewed 05 May 2017, from http://www.weathersa.co.za/ floods

Schulze, B.R., 1972, World survey of climatology, Ed. Landsberg, pp. 501-555, Elsevier, Amsterdam.

Shin, H., Jung, Y., Jeog, C. \& Heo, J.H., 2011, Assessment of modified Anderson-Darling test statistics for generalised extreme value and generalised logistic distributions, viewed 20 May 2017, https:// www.researchgate.net/publication/225839062

Simpson, J., 1996, 'Precipitation augmentation from cumulus clouds and systems: Scientific and technology foundation', Advances in Geophysics 19, 1-8.

Smithers, J.C. \& Schulze, R.E., 2001, 'A methodology for the estimation of short duration design storms in South Africa using a regional approach based on L-moments', Journal of Hydrology 42-52, viewed 09 May 2017, from http://www. wrc.org.za/Knowledge $\% 20 \mathrm{Hub} \% 20$ Documents/.../1060\%20web

Smithers, J.C., Schulze, R.E., Pike, A. \& Jewitt, G.P.W., 2000, A hydrological perspective of the February 2000 floods (A case study in the Sabie River Catchment), viewed 13 May 2017, from www.wrc.org.za/Knowledge $\% 20$ Hub\%20Documents/.../ WaterSA 2001 03 1377.pdf

Stedinger, J.R., Vogel, R.M. \& Batchelder, R., 2008, 'Appraisal of the generalized likelihood uncertainty estimation (GLUE) method', Water Resources Research 44, W00B06. https://doi.org/10.1029/2008WR006822

Stedinger, J.R., Vogel, R.M. \& Foufoula-Georgiou, E., 1993, Frequency analysis of extreme events, viewed 16 May 2017, from http://www.researchgate.net

Wahlstrom, M. \& Guha-Sapir, D., 2015, UN- 1995-2015 flood report: Cop21 WeatherDisasterReports_2014, viewed 19 May 2017, from http://www.Floodlist. com/dealing with floods/flood figures 1995-2015

Weibull, W., 1939, Statistical theory of strength of materials, viewed 18 May 2017, from http://www.scrip.org 